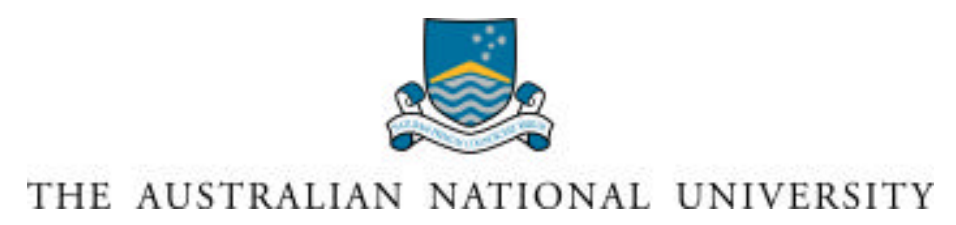

Working Paper Series in Finance 00-10

\title{
PRICING THE SPI FUTURES CALL OPTION CONTRACT USING THE ASAY MODEL
}

\author{
Chakriya Bowman \\ Department of Commerce \\ Australian National University
}

JEL Classification

G13

Keywords

Futures options; Options pricing; Asay model

Last revision date:

June 2000

Contact author:

Cha Bowman

Department of Commerce

The Australian National University

Canberra ACT 0200 AUSTRALIA

Telephone: 0262490025 (International +61 26249 0025)

Facsimile: 0262495005 (International +61 26249 5005)

Email: chakriya.bowman@absalom.com.au

The working paper series is for manuscripts in draft form. Comments are welcome and should be sent to the contact author. Please do not quote without permission.

(C) Copyright 2000 C. Bowman 


\title{
Pricing the SPI Futures call option contract using the Asay model
}

\section{Chakriya Bowman}

\author{
Department of Commerce
}

Australian National University

\begin{abstract}
This paper examines the relative pricing performance of the Asay (1986) futures option pricing model on the All Ordinaries Share Price Index Futures Call Option contract over the period January 1993- September 1995. A dataset of 8,092 matched tick-by-tick transactions in SPI future options is examined, and the Asay model is used to generate pricing estimates for the options. This theoretically derived data is then compared against the real price data, and pricing anomalies are observed. Pricing biases are categorised in terms of time to maturity, and examined in terms of unit error and absolute percentage error. Conclusions are drawn as to the relative efficiency of the model with regard to systematic errors.
\end{abstract}




\section{Introduction}

The Sydney Futures Exchange offers a put and call option on the All Ordinaries Share Price Index (SPI) futures contract. This contract is an American-style contract, that pays no dividends and is marked-to-market at the close of business each trading day. The contracts are written to mature in each quarter (March, June, September and December) and to a maximum time-to-maturity of 18 months. These contracts mature on the last trading day of the month of expiry, at which point they are cash settled. The value of the option is marked to market each day, and gains and losses collected. Almost 20,000 SPI futures and options contracts are traded on the SFE each day, and the contracts are one of the most liquid derivative product in the Australian market. The contracts are priced at $\$ 25$ times the number of points of the contract. The contracts can be traded both during normal day trading sessions, and also may be traded overnight. ${ }^{1}$

This flavour of futures option, the pure futures option, is found on the Sydney Futures Exchange (SFE), and the London International Financial Futures Exchange (LIFFE). The SFE offers futures options on a range of products other than the SPI index futures, including options on 90-day Bank-Accepted Bill futures, options on 10-year and 3-year Commonwealth Treasury bond futures, options on Dow Jones AP/ELS Australia Index futures, as well as options on a range of commodity futures, such as greasy wool futures and wheat futures. The LIFFE trades a range of futures options on products such as the British Pound and the UK treasury bond ( or "gilt").

Since the recent changes to the All Ordinaries index, and the branding of several products under the S\&P name, the S\&P/ASX 200 will be the basis for the SPI futures contracts traded after May 2000.

\section{Literature Review}

\subsection{The Futures Option - Early Work}

The futures option presents a number of interesting pricing issues due to the nature of the option. As a futures based product, it is marked to market on a daily basis, removing any need to factor an interest rate component into the calculations of price. This is why the SPI index futures option is known as a "pure" option. The Asay (1982) paper first examined the concept of a pure commodity futures based option, starting from what is known as the modified Black (1976) model for European commodity futures options. This is based on the formula:

$$
\mathrm{C}(\mathrm{F}, \mathrm{T}, \mathrm{X})=\mathrm{e}^{-\mathrm{rT}}\left[\mathrm{F}^{*} \mathrm{~N}\left(\mathrm{~d}_{1}\right)-\mathrm{X}^{*} \mathrm{~N}\left(\mathrm{~d}_{2}\right)\right]
$$

where

$$
\begin{gathered}
\mathrm{d}_{1}=\frac{\ln (\mathrm{F} / \mathrm{X})+1 / 2^{*} \sigma^{2} * \mathrm{~T}}{\sigma \sqrt{ } \mathrm{T}} \\
\mathrm{d}_{2}=\mathrm{d}_{1}-\sigma \sqrt{ } \mathrm{T}
\end{gathered}
$$

\footnotetext{
${ }^{1}$ It should be noted that the Sydney Futures Exchange uses the Asay model to calculate the value of margin deposits.
} 
The model makes a number of assumptions, these being

1. All transaction costs are ignored

2. Markets are free of costless arbitrage opportunities

3. The short-term risk-free rate is constant over time

4. The instantaneous futures price change relative is a stochastic process

Note that this implies the value of the option relative to the futures price is lower than the value of the option relative to the physical commodity, as the futures price already reflects the carrying charges inherent in the cost of the physical commodity.

Asay takes the Black model a step further. The futures option contract is marked to market on a daily basis, and hence no premium flows from the purchaser to the seller immediately. Asay shows that there is a convergence of the initial premium to the settlement price at expiration. Since risk-free hedges may be created between the underlying futures contract and the option, the interest rate component has no influence over the pricing of the model and so can be written as

$$
\mathrm{C}(\mathrm{F}, \mathrm{T}, \mathrm{X})=\mathrm{F}^{*} \mathrm{~N}\left(\mathrm{~d}_{1}\right)-\mathrm{X}^{*} \mathrm{~N}\left(\mathrm{~d}_{2}\right)
$$

with $d_{1}$ and $d_{2}$ as given by the Black model in (2) above. Asay states that the underlying commodity, the futures contract, provides pure financial leverage to the cash commodity while the futures option provides pure insurance. The futures option contract also provides a vehicle for complete integration of options with the futures market.

\subsection{The Pure Futures Option - Australia}

Asay discussed the features of the futures option contract, particularly the fact that the interest rate component $\mathrm{e}^{-\mathrm{rT}}$ could be omitted from the equation due to the fact that risk free hedges between the futures contract and the option can be established with no investment of funds, thus eliminating the need to factor in the holding cost of these funds. This "pure" option concept ${ }^{2}$ is particularly applicable to the SPI future option contract, which is marked to market daily and does not require the purchaser to pay the option premium at the time of establishing a position.

$$
\mathrm{C}(\mathrm{F}, \mathrm{T}, \mathrm{X})=\mathrm{F}^{*} \mathrm{~N}\left(\mathrm{~d}_{1}\right)-\mathrm{X}^{*} \mathrm{~N}\left(\mathrm{~d}_{2}\right)
$$

where

$$
\begin{gathered}
\mathrm{d}_{1}=\frac{\ln (\mathrm{F} / \mathrm{X})+1 / 2^{*} \sigma^{2} \mathrm{~T}}{\sigma \sqrt{ } \mathrm{T}} \\
\mathrm{d}_{2}=\mathrm{d}_{1}-\sigma \sqrt{ } \mathrm{T}
\end{gathered}
$$

\footnotetext{
2 The naming convention "pure futures option" will be used to denote options with futures-style markingto-market, while "conventional futures option" refers to the style of futures option found in the US and other markets which does not have this margining requirement.
} 
Lieu (1990) shows that because it will never be optimal to exercise a pure American futures option early, its value will be that of a pure European futures option, and its price will never fall below the intrinsic value of the option. Hence we can model the pure American futures option, such as the SPI futures option, as a European option with a lower bound of the intrinsic value of the option. Lieu also points out that the futures-style margining properties of the pure futures option turn the option into a futures contract on a stock-style option, as was discussed by Duffie (1989).

Chaudhury and Wei (1994) further show that the pure futures option price is in fact an upper bound of the conventional American futures option. The bounds of the option can be described such that

$$
\mathrm{C}(\mathrm{F}, \mathrm{T}, \mathrm{X})=\max (0, \mathrm{~F}(\mathrm{~T})-\mathrm{X})
$$

where $\mathrm{T}$ is the date of expiry.

\subsection{The Conventional Futures Option - United States}

There is no equivalent US based product to the pure futures option, and hence most literature addresses issues in the US conventional futures options market. The conventional futures option contract does not have a margining requirement, and it requires the purchaser to pay the option premium when the transaction is initiated. This premium is then credited to the account of the option seller, who must maintain the margin account against the value of the option over time.

Whaley (1986) examined the conventional futures option, again starting with the modified Black (1976) model for European conventional futures options, and progressing through to a valuation of the American style conventional futures option. This work drew attention to the early exercise premium of the American conventional futures option, which was found to have a significant effect on pricing for in-the-money options.

Further work based on the conventional futures option was done by Barone-Adesi and Whaley (1987). This work proposed a model to approximate the value of the American conventional futures option, taking the early exercise premium into account. This model is based on Macmillan's quadratic approximation of the American put option on a non-dividendpaying stock, after eliminating the component representing the cost of carrying the underlying commodity, since there is no cost of carrying a futures position. The model developed was, at the time, the most computationally efficient model implemented, while providing a good level of accuracy.

Improvements in conventional futures option pricing models continued throughout the late 1980s and early 1990s, with particular emphasis on the development of computationally efficient models, that would trade accuracy for computational speed. Chaurdhury (1995) proposes four methods to value American conventional futures options, which retain the closed form, analytic nature of the Black (1976) European futures option valuation, and allow a more computationally efficient solution to the pricing problem. Of particular interest is the application of futures options to estimate implied volatility of spot options, due to the liquidity 
of the market and the lack of dependence of the estimation on yield on the spot asset. Chaudhury's four models offered fast, accurate and efficient calculation methods that could be used by practitioners in preference to the modified Black (1976) model. The multiplicative valuation framework that these models used also showed that marking-to-market a European futures option was more valuable than either adding the early exercise premium, or markingto-market an American futures option. The methods could also be implemented as a group depending on the moneyness and maturity characteristics of the option, as it was shown that the different models performed best under different situations. It was also shown that they produced preferable implied volatility calculations to the modified Black formula, as they did not contain the upward bias in estimates that is evident in the modified Black model.

However, the advances in personal computing power in the latter part of the 1990s has eliminated most of the need for more computationally efficient solutions. As a result, little progressive research has taken place in the area of futures option pricing since the mid 1990s.

\subsection{Implied Volatility}

While not the focus of this study, the choice of methods to determine the volatility measure used in the Asay calculations impacts on the final outcome. The Asay model assumes continuously compounded rates of return, following a normal distribution pattern with a constant mean and constant variance at some point in time. This variance is then extrapolated to produce an estimate of volatility over the remaining time to maturity of the contract. The volatility input to the equation is an important component to determining the final outcome, and there are many studies that examine and contrast implied volatility measures.

Historical volatility is often used as a proxy for volatility, based on the assumption that the events of the past are likely to influence the events of the future. Hence the historical volatility can be seen as a way to predict future volatility movements. However, the historical volatility does not compensate for changes in volatility levels through time. If the level of volatility remains stable, then the historical volatility will be a good proxy for future volatility. However, should the volatility become unstable, then the historical volatility will not be an effective proxy for future volatility.

Implied volatility is a method by which the volatility is determined from a model, using actual pricing data and working backwards to determine the volatility from the other known parameters of the function. Research ${ }^{3}$ has found that the use of an implied volatility measure generates better predictions of future prices than historical volatility. The Asay model, and futures options, are widely used in industry as a method to calculate the volatility of the underlying futures contracts. There are several methods that can be used to calculate the implied volatility from transactions in the futures options market. The previous nearest-to-themoney trade can be used to generate a volatility that may then be used as the measure for subsequent estimations. The average volatility for the previous days trades can also be used, and there are variations on this theme, such as the weighted-average implied volatility. Using an average does not take into account the efficiency of the pricing model, and puts equal

\footnotetext{
${ }^{3}$ See Brown and Shevlin (1983) among others
} 
weighting on badly mispriced options as it does on efficiently priced options. Using a weighting system, which biases the average toward the efficiently priced options, should help to minimize this effect. Beckers (1981) showed that using the nearest-to-the-money option forecast future volatility as well as any of the several weighting methods he examined, and other research has looked at other ways to weight and estimate implied volatility.

\section{Methodology}

The futures and futures option datasets were initially loaded into Microsoft SQL Server, a database program used widely in the IT and internet industries, which is designed to perform fast processing on large quantities of data. The data was sorted and a query that matched the transactions based on timestamp, using an iterative loop that proved too computation intensive for the machine being used ${ }^{4}$. A faster but more labour-intensive method was used to systematically work through the time differences in transactions until the window of 60 seconds either side of the transaction had been covered. A lag relationship was given priority over a lead relationship for the same timestamp difference, i.e. a futures transaction occurring 3 seconds prior to the option transaction was matched before a futures transaction occurring 3 seconds after the option transaction ${ }^{5}$. The resulting data file, containing the futures transaction price, the futures option strike price, the futures option transaction price, and the time to maturity of the futures option was then used for subsequent calculations.

Due to the heavy focus of this project on numerical calculations, a widely-used Engineeringstyle software program, Matlab, was used to analyse the data. Matlab provides a wide range of functionality that has financial analysis applications as well as engineering applications.

The resulting software was developed over several weeks and examples of this software can be found in the Appendix. Matlab provides an ideal foundation for the mathematical and analytical calculations while the SQL database allows the complex SQL statements to be run over a large quantity of data.

\subsection{Implied Volatility}

Implied volatility was calculated by a Matlab function ${ }^{6}$ using an iterative loop to solve for

$$
\mathrm{C}-\mathrm{P} \Rightarrow 0
$$

where $\mathrm{C}$ is the calculated futures option price (using the Asay model) and $\mathrm{P}$ is the actual price of the transaction that occurred

The process is seeded with a high volatility measure of 1 , and a low volatility measure of 0 . Having seeded the model, the high and low values are used to calculate the Asay price. If the difference between one of the Asay calculations and the actual transaction price is less than 0.00001 , the calculation is determined to have reached the desired level of accuracy and becomes the volatility measure. Otherwise, the loop iterates through a series of calculations

\footnotetext{
${ }^{4}$ Pentium 233 MMX with 64M RAM

${ }^{5}$ The issue of preferential treatment of lead and lag relationships is discussed in the final section.

${ }^{6}$ See Appendix A
} 
against the average of the high and low values, and reassigns the high and low values according to the difference between their results and that of the average with respect to the actual option price.

The implied volatility values were then used to calculate the Asay model prices for the following days trade in that specific contract using one of two methods:

1. An average implied volatility (AIV), based simply on the average implied volatility for each trading day, was calculated, and this matched to the next day's transactions to be used to calculate the Asay expected price.

$$
\begin{gathered}
\operatorname{AIV}=\Sigma \sigma_{\mathrm{i}} \\
\operatorname{Asay}\left(\mathrm{F}_{t}, \mathrm{X}_{t}, \mathrm{~T}_{t}, \sigma_{t}\right)=\operatorname{Asay}\left(\mathrm{F}_{t}, \mathrm{X}_{t}, \mathrm{~T}_{t}, \mathrm{AIV}_{\mathrm{t}-1}\right)
\end{gathered}
$$

2. The implied volatility of the option nearest to the money (NMIV) was also determined, and this was likewise matched to the next day's transactions to be used in Asay expected price calculations.

$$
\begin{gathered}
\text { NMIV }=\sigma_{i} \quad \text { for the transaction where F- } X \Rightarrow 0 \\
\operatorname{Asay}\left(F_{t}, X_{t}, T_{t}, \sigma_{t}\right)=\operatorname{Asay}\left(F_{t}, X_{t}, T_{t}, N_{M I V}{ }_{t-1}\right)
\end{gathered}
$$

This method of estimation poses some problems due to thin trading issues when futures options are particularly long dated. In some instances, the futures option may be traded only once in an entire week. This makes volatility estimations particularly difficult. A number of papers $^{7}$ have solved this problem by using only short-dated, regularly traded options. However, this study of longer dated options is interesting, since we know that the futures options are often relied upon to calculate implied volatility for the underlying futures contract. Any mispricing effect present in long-dated options will detract from the accuracy of the implied volatility measurement.

A Matlab function ${ }^{8}$ was then used to match the implied volatility measures with the following day's transaction.

\footnotetext{
${ }^{7}$ Brown and Taylor (1997)

${ }^{8}$ See Appendix B
} 


\section{Pricing Errors}

The data file containing futures trade price, futures option strike price, futures option trade price, time to maturity and volatility measure was run through a Matlab function that calculated the Asay price (AP) for each data set and determined the pricing errors for each calculation based on the actual price of the futures option transaction (OP).

The pricing error measurements used were:

1. MPE - Mean Pricing Error

This is the sum of all pricing errors for the data set, divided by the total number of transactions in the data set, to give the average pricing error.

$\mathrm{MPE}=1 / \mathrm{n} * \Sigma\left(\mathrm{OP}_{\mathrm{n}}-\mathrm{AP}_{\mathrm{n}}\right)$

2. MAPE - Mean Absolute Pricing Error

This is the sum of the magnitude of each pricing error, divided by the total number of transactions in the data set, to give the average absolute pricing error.

$\mathrm{MPE}=1 / \mathrm{n} * \Sigma \operatorname{abs}\left(\mathrm{OP}_{\mathrm{n}}-\mathrm{AP}_{\mathrm{n}}\right)$

3. MARPE - Mean Absolute Relative Pricing Error

The absolute value of the pricing error expressed as a percentage of the actual transaction price.

$\operatorname{MARPE}=1 / \mathrm{n} * \Sigma\left(\operatorname{abs}\left(\mathrm{OP}_{\mathrm{n}}-\mathrm{AP}_{\mathrm{n}}\right) / \mathrm{OP}_{\mathrm{n}}\right)$

4. MEDARPE - Median Absolute Relative Pricing Error

This is the median of the absolute relative pricing errors. An array of the MARPE values is created and the median for this set determined.

Additionally, the number of positive errors (i.e. $\mathrm{OP}_{\mathrm{n}}-\mathrm{AP}_{\mathrm{n}}>0$ ) is also recorded.

\section{Data}

The dataset used for this thesis consists of tick-by-tick transactions for all SPI futures and SPI futures options contracts traded between $1^{\text {st }}$ January 1993 and $31^{\text {st }}$ August 1995 . This gives a dataset of 11,777 futures call options transactions, and 526,849 futures transactions with details of exact date and time of the trade to seconds, strike, price, contract year and month of expiry. The futures dataset was matched with the futures options dataset such that the SPI futures option transaction was matched to the nearest futures transaction within a 60 second window either side of the futures option transaction. 
The potential data set contained 8144 matched transactions. Of this set, only 16 transactions were matched for contracts dated 12/1995, and so these were discarded. 11 transactions were dated 12/2004 and 12/2005. These transactions all occurred on the last trading days of 1994 and 1995 respectively, and would appear to be the result of a computer glitch. While they may have been valid trades for the 1994 and 1995 years, and were simply incorrectly dated, these trades were discarded as this could not be confirmed. 22 pairs were removed as they contravened arbitrage bounds such that

$$
\mathrm{C}<=\mathrm{F}-\mathrm{X}
$$

This left a dataset of 8,092 transaction pairs that were then split into groups according to their maturity date. These maturity groups ("calls") were then split into sub-groups, with a group consisting of trades with greater than 3 calendar months to maturity ("long"), and trades with 3 or fewer calendar months to maturity ("short"). No "long" dataset was available for the $3 / 1993$ contracts as suitable transactions occurred before the start of the data set.

Table 1 : Breakdown of Data Set

\begin{tabular}{|c|c|c|c|}
\hline & Short & Long & Calls \\
\hline $3-1993$ & 421 & - & 421 \\
\hline $6-1993$ & 406 & 55 & 461 \\
\hline $9-1993$ & 514 & 34 & 548 \\
\hline $12-1993$ & 835 & 73 & 908 \\
\hline $3-1994$ & 1168 & 64 & 1232 \\
\hline $6-1994$ & 692 & 93 & 785 \\
\hline $9-1994$ & 542 & 86 & 628 \\
\hline $12-1994$ & 632 & 90 & 722 \\
\hline $3-1995$ & 623 & 62 & 685 \\
\hline $6-1995$ & 940 & 79 & 1019 \\
\hline $9-1995$ & 589 & 94 & 683 \\
\hline
\end{tabular}




\section{Results}

\subsection{All Call Options}

Tables 2 and 3 show the pricing metrics obtained from the AIV and NMIV calculations respectively.

Table 2: All Contracts, AIV

\begin{tabular}{|r|r|r|r|r|r|r|}
\hline & \multicolumn{1}{|l|}{ MPE } & MAPE & MARPE & MEDARPE & $\begin{array}{l}\text { Number } \\
\text { of } \\
\text { Positive } \\
\text { Errors }\end{array}$ & $\begin{array}{l}\text { Total } \\
\text { Data } \\
\text { Count }\end{array}$ \\
\hline $3-1993$ & 0.993467597 & 20.02116632 & 0.12674844 & 0.062603318 & 207 & 417 \\
\hline $6-1993$ & -1.628407047 & 22.7761039 & 0.140628169 & 0.086667261 & 231 & 460 \\
\hline $9-1993$ & -1.076770593 & 23.64266815 & 0.13585314 & 0.061713649 & 265 & 547 \\
\hline $12-1993$ & -0.463729915 & 22.26730197 & 0.111753368 & 0.059365146 & 413 & 907 \\
\hline $3-1994$ & 2.569257405 & 27.86112518 & 0.097690005 & 0.050769953 & 608 & 1231 \\
\hline $6-1994$ & 1.520963048 & 28.73146489 & 0.175207468 & 0.056622686 & 368 & 784 \\
\hline $9-1994$ & -0.252155466 & 22.66966005 & 0.120433948 & 0.059349851 & 286 & 627 \\
\hline $12-1994$ & -1.695600875 & 20.66415883 & 0.126797085 & 0.061568396 & 307 & 721 \\
\hline $3-1995$ & -0.904186654 & 14.3037605 & 0.080747747 & 0.044835206 & 298 & 682 \\
\hline $6-1995$ & 0.719636634 & 19.79926906 & 0.13146325 & 0.060595791 & 509 & 1018 \\
\hline $9-1995$ & -0.366029605 & 17.78730494 & 0.058518326 & 0.038629988 & 298 & 682 \\
\hline Mean & $-\mathbf{0 . 0 5 3 0 5 0 4 9 7}$ & $\mathbf{2 1 . 8 6 5 8 1 6 7 1}$ & $\mathbf{0 . 1 1 8 7 1 2 8 1 3}$ & $\mathbf{0 . 0 5 8 4 2 9 2 0 4}$ & $\mathbf{3 7 9 0}$ & $\mathbf{8 0 7 6}$ \\
\hline
\end{tabular}

Table 3: All Contracts, NMIV

\begin{tabular}{|r|r|r|r|r|r|r|}
\hline & \multicolumn{1}{|l|}{ MPE } & MAPE & MARPE & MEDARPE & $\begin{array}{l}\text { Number } \\
\text { of } \\
\text { Positive } \\
\text { Errors }\end{array}$ & $\begin{array}{l}\text { Total } \\
\text { Data } \\
\text { Count }\end{array}$ \\
\hline $3-1993$ & -1.628353394 & 20.92335197 & 0.134609099 & 0.064693628 & 187 & 417 \\
\hline $6-1993$ & -5.293545339 & 24.42599412 & 0.150456235 & 0.095679744 & 198 & 460 \\
\hline $9-1993$ & -3.724264951 & 24.71502498 & 0.142231371 & 0.064792859 & 245 & 547 \\
\hline $12-1993$ & -7.940574189 & 24.76616173 & 0.13152345 & 0.063792347 & 343 & 907 \\
\hline $3-1994$ & -1.600740912 & 32.96880768 & 0.123283961 & 0.055793555 & 545 & 1231 \\
\hline $6-1994$ & -11.55805938 & 33.24269042 & 0.21636456 & 0.070009534 & 267 & 784 \\
\hline $9-1994$ & -9.911491416 & 25.48605052 & 0.139387488 & 0.065304815 & 236 & 627 \\
\hline $12-1994$ & -7.652388703 & 25.46290803 & 0.162376497 & 0.084851552 & 278 & 721 \\
\hline $3-1995$ & -1.880684392 & 18.95284601 & 0.103716546 & 0.059049311 & 307 & 682 \\
\hline $6-1995$ & -0.577773795 & 20.12672702 & 0.11890736 & 0.060248066 & 460 & 1018 \\
\hline $9-1995$ & -6.396911467 & 21.18424347 & 0.074937805 & 0.046162915 & 266 & 682 \\
\hline Mean & $-\mathbf{5 . 2 8 7 7 0 7 9 9 5}$ & $\mathbf{2 4 . 7 5 0 4 3 6 9}$ & $\mathbf{0 . 1 3 6 1 6 3 1 2 5}$ & $\mathbf{0 . 0 6 6 3 9 8 0 3}$ & $\mathbf{3 3 3 2}$ & $\mathbf{8 0 7 6}$ \\
\hline
\end{tabular}


A greater pricing error was found using the NMIV method to calculate implied volatility. In the case of the NMIV calculations, the MPE shows clearly that the Asay model consistently overpriced the futures option. The MARPE shows that the option was overpriced by $11.87 \%$ in the case of the AIV calculations, and by just over $13.61 \%$ when using NMIV. This overpricing appears to be systematic in the case of the NMIV calculations, as negative pricing errors persist over the entire sample period. This bias is more evident in the case of NMIV calculations, where 4744 out of 8076 transactions were negative, or $58.74 \%$, while 4286 out of 8076 transactions, or $53.07 \%$ of the AIV calculations were negative. The median percentage pricing error lies at $5.84 \%$ for AIV calculations, and $6.64 \%$ for NMIV calculations.

Graphs of time-to-maturity vs. implied volatility for both the AIV and NMIV can be found in Appendix F and Appendix G respectively.

\subsection{Short-Dated Call Options}

Tables 4 and 5 show the pricing metrics obtained from the AIV and NMIV calculations for short-dated futures options.

Table 4: Short Contracts, AIV

\begin{tabular}{|r|r|r|r|r|r|r|}
\hline & \multicolumn{1}{|l|}{ MPE } & MAPE & MARPE & MEDARPE & $\begin{array}{l}\text { Number } \\
\text { of } \\
\text { Positive } \\
\text { Errors }\end{array}$ & $\begin{array}{l}\text { Total } \\
\text { Data } \\
\text { Count }\end{array}$ \\
\hline $3-1993$ & 0.993467597 & 20.02116632 & 0.12674844 & 0.062603318 & 207 & 417 \\
\hline $6-1993$ & -0.660017767 & 21.86217809 & 0.147425174 & 0.092929854 & 210 & 406 \\
\hline $9-1993$ & -0.268280198 & 22.11904265 & 0.133848429 & 0.059890193 & 247 & 514 \\
\hline $12-1993$ & -0.503968656 & 21.18712351 & 0.107972219 & 0.055783581 & 382 & 835 \\
\hline $3-1994$ & 2.563988106 & 27.54789077 & 0.099666176 & 0.050861603 & 581 & 1168 \\
\hline $6-1994$ & -0.356029432 & 26.62959474 & 0.184327282 & 0.053869651 & 322 & 692 \\
\hline $9-1994$ & -0.417125902 & 20.29924432 & 0.113107776 & 0.055178964 & 248 & 542 \\
\hline $12-1994$ & -2.569297928 & 19.30382953 & 0.130568507 & 0.061583333 & 260 & 632 \\
\hline $3-1995$ & -1.738719347 & 13.05113894 & 0.080894031 & 0.042649093 & 267 & 623 \\
\hline $6-1995$ & 1.263035445 & 19.23201148 & 0.133065347 & 0.060683911 & 476 & 940 \\
\hline $9-1995$ & -0.6430194 & 16.02748025 & 0.053482454 & 0.037906199 & 252 & 589 \\
\hline Mean & $-\mathbf{0 . 2 1 2 3 6 0 6 8}$ & $\mathbf{2 0 . 6 6 1 8 8 1 8 7}$ & $\mathbf{0 . 1 1 9 1 9 1 4 4}$ & $\mathbf{0 . 0 5 7 6 3 0 8 8 2}$ & $\mathbf{3 4 5 2}$ & $\mathbf{7 3 5 8}$ \\
\hline
\end{tabular}


Table 5: Short Contracts, NMIV

\begin{tabular}{|r|r|r|r|r|r|r|}
\hline & \multicolumn{1}{|l|}{ MPE } & MAPE & \multicolumn{1}{l|}{ MARPE } & MEDARPE & \multicolumn{1}{l|}{$\begin{array}{l}\text { Number } \\
\text { of } \\
\text { Positive } \\
\text { Errors }\end{array}$} & \multicolumn{1}{l|}{$\begin{array}{l}\text { Total } \\
\text { Data } \\
\text { Count }\end{array}$} \\
\hline $3-1993$ & -1.628353394 & 20.92335197 & 0.134609099 & 0.064693628 & 187 & 417 \\
\hline $6-1993$ & -4.519842532 & 22.85787734 & 0.15617911 & 0.098917836 & 181 & 406 \\
\hline $9-1993$ & -3.133740631 & 23.46048757 & 0.141242866 & 0.064381145 & 227 & 514 \\
\hline $12-1993$ & -6.823064752 & 23.31384886 & 0.122841689 & 0.063228103 & 322 & 835 \\
\hline $3-1994$ & -2.276426344 & 33.10911016 & 0.127129449 & 0.057742322 & 513 & 1168 \\
\hline $6-1994$ & -10.35661271 & 31.28932249 & 0.22788932 & 0.06662098 & 240 & 692 \\
\hline $9-1994$ & -7.602282048 & 22.91043314 & 0.12756639 & 0.06150785 & 213 & 542 \\
\hline $12-1994$ & -7.979219319 & 24.64297481 & 0.169717986 & 0.092611786 & 238 & 632 \\
\hline $3-1995$ & -1.228371959 & 18.05813506 & 0.104512911 & 0.056932453 & 282 & 623 \\
\hline $6-1995$ & 0.592473 & 19.05230905 & 0.115180187 & 0.058422093 & 439 & 940 \\
\hline $9-1995$ & -5.590360564 & 18.55029859 & 0.067403337 & 0.04256479 & 234 & 589 \\
\hline Mean & $-\mathbf{4 . 5 9 5 0 7 2 8 4 1}$ & $\mathbf{2 3 . 4 6 9 8 3 1 7 3}$ & $\mathbf{0 . 1 3 5 8 4 2 9 4}$ & $\mathbf{0 . 0 6 6 1 4 7 5 4 4}$ & $\mathbf{3 0 7 6}$ & $\mathbf{7 3 5 8}$ \\
\hline
\end{tabular}

The short-dated contracts are considerably more liquid than the long-dated contracts, and it would be anticipated that they would reflect an improved degree of accuracy in the Asay model calculations. The mean pricing error is reduced in the case of the NMIV calculations, but the AIV calculations actually show an increase in pricing error.

The percentage of options overpriced by the AIV model has not changed substantially - from $53.07 \%$ for the all contracts sample, to $53.08 \%$ for the short contracts sample. While the mean absolute percentage error has decreased slightly, from 21.86 to 20.66 , the mean absolute percentage error has increased slightly, from $11.87 \%$ to $11.91 \%$.

The shorter dated sample has improved the performance of the NMIV model. The mean error has reduced from -5.28 to -4.59 , and the absolute error has likewise reduced from 24.75 to 23.47 , both of which are substantial improvements in performance. The percentage error has also fallen, from $6.63 \%$ to $6.61 \%$, and the percentage of overpriced options has fallen from $58.74 \%$ to $58.19 \%$. 


\subsection{Long-Dated Call Options}

Table 6 and 7 show the pricing metrics obtained from the AIV and NMIV calculations for long-dated futures options.

Table 6: Long Dated Contracts, AIV

\begin{tabular}{|r|r|r|r|r|r|r|}
\hline & \multicolumn{1}{|l|}{ MPE } & MAPE & MARPE & MEDARPE & $\begin{array}{l}\text { Number } \\
\text { of } \\
\text { Positive } \\
\text { Errors }\end{array}$ & $\begin{array}{l}\text { Total } \\
\text { Data } \\
\text { Count }\end{array}$ \\
\hline $3-1993$ & - & & - & - & - & - \\
\hline $6-1993$ & -8.90925978 & 29.64747205 & 0.08952476 & 0.047062987 & 21 & 54 \\
\hline $9-1993$ & -13.66962099 & 47.37428972 & 0.167078018 & 0.141312644 & 18 & 33 \\
\hline $12-1993$ & 0.002927714 & 34.79437172 & 0.155604195 & 0.079156824 & 31 & 72 \\
\hline $3-1994$ & 2.666948531 & 33.66839172 & 0.061052407 & 0.04994171 & 27 & 63 \\
\hline $6-1994$ & 15.63921084 & 44.54118383 & 0.10661061 & 0.080815137 & 46 & 92 \\
\hline $9-1994$ & 0.799773662 & 37.78454619 & 0.167149072 & 0.083315718 & 38 & 85 \\
\hline $12-1994$ & 4.508629888 & 30.32402532 & 0.100015749 & 0.059214269 & 47 & 89 \\
\hline $3-1995$ & 7.907912796 & 27.53059497 & 0.079203078 & 0.065330445 & 31 & 59 \\
\hline $6-1995$ & -5.829015704 & 26.63545014 & 0.112155922 & 0.05957435 & 33 & 78 \\
\hline $9-1995$ & 1.388239098 & 28.93286134 & 0.090412181 & 0.050753892 & 46 & 93 \\
\hline Mean & $\mathbf{0 . 4 5 0 5 7 4 6 0 5}$ & $\mathbf{3 4 . 1 2 3 3 1 8 7}$ & $\mathbf{0 . 1 1 2 8 8 0 5 9 9}$ & $\mathbf{0 . 0 7 1 6 4 7 7 9 8}$ & $\mathbf{3 3 8}$ & $\mathbf{7 1 8}$ \\
\hline
\end{tabular}

Table 7: Long Dated Contracts, NMIV

\begin{tabular}{|c|c|c|c|c|c|c|}
\hline & MPE & MAPE & MARPE & MEDARPE & $\begin{array}{l}\text { Number } \\
\text { of } \\
\text { Positive } \\
\text { Errors } \\
\end{array}$ & $\begin{array}{l}\text { Total } \\
\text { Data } \\
\text { Count }\end{array}$ \\
\hline $3-1993$ & - & & - & - & - & \\
\hline $6-1993$ & -11.11064423 & 36.21590919 & 0.107428695 & 0.063460432 & 17 & 54 \\
\hline $9-1993$ & -12.92212861 & 44.2553955 & 0.157628084 & 0.121396469 & 18 & 33 \\
\hline $12-1993$ & -20.90057948 & 41.60895687 & 0.232207768 & 0.082245182 & 21 & 72 \\
\hline $3-1994$ & 10.9262525 & 30.36764421 & 0.051989829 & 0.032035184 & 32 & 63 \\
\hline $6-1994$ & -20.59502783 & 47.93541436 & 0.129678315 & 0.082089476 & 27 & 92 \\
\hline $9-1994$ & -24.63609703 & 41.90939901 & 0.214764372 & 0.096330227 & 23 & 85 \\
\hline $12-1994$ & -5.331524105 & 31.28535517 & 0.110243679 & 0.056781524 & 40 & 89 \\
\hline $3-1995$ & -8.768661445 & 28.40038702 & 0.095307462 & 0.086640317 & 25 & 59 \\
\hline $6-1995$ & -14.68074799 & 33.07484097 & 0.163824571 & 0.077058197 & 21 & 78 \\
\hline $9-1995$ & -11.50506719 & 37.86589438 & 0.122656099 & 0.072321507 & 32 & 93 \\
\hline Mean & -11.95242254 & 37.29191967 & 0.138572887 & 0.077035852 & 256 & 718 \\
\hline
\end{tabular}


Inherent in this study is the problem of thin trading bias in long-dated contracts. However, the long-dated contracts yield some interesting information. While the NMIV model becomes less accurate in pricing the contracts, the performance of the AIV model actually appears to improve. There is a less significant bias toward overpricing the longer-dated contracts, with $52.92 \%$ of values being overpriced, compared to more than 53\% with the shorter-dated contracts. Likewise the mean absolute pricing error decreases from $11.91 \%$ to $11.28 \%$. The mean absolute pricing error is significantly larger, at 34.12 compared to 20.66 for the shortdated contracts, and the mean pricing error is likewise larger, and now positive, at 0.45 compared with -0.21 for the short-dated contracts.

The NMIV model's performance has deteriorated significantly, with $64.34 \%$ of calculated values overpricing the option. The mean absolute relative pricing error has increased from $13.58 \%$ for the short-dated contracts, to $13.86 \%$ for the long-dated contracts. The mean pricing error is -11.95 , compared with -4.59 for the shorter contracts. The mean has also increased by 0.011 , from 0.066 to 0.077 .

\subsection{Analysis}

The results of the long-dated contracts are perhaps the most interesting in this study. It would be expected that the difference between the AIV and NMIV calculations would not be so great. Since there are fewer transactions occurring, and on many days only one transaction has been matched, the average is likely to be identical to the near-money value. It was anticipated that there would not be such a significant disparity between these two measures. It was also anticipated that, as the time to maturity increases, the accuracy of pricing and volatility calculation would decrease, and there would be an increase in the mispricing of the contracts. The AIV model shows that this is not the case, and actually performs better percentage-wise than in the case of short-dated contracts. This would indicate that the average volatility is perhaps more consistent over time when some distance from the expiry date.

The average implied volatility measure was consistently better in estimating the model than the volatility taken from the nearest-the-money option. In each case the magnitude of the mispricing was lower, and the total number of options that were overpriced were fewer.

Throughout the sample, the Asay model was significantly biased towards overpricing the futures option contracts. This was not anticipated - in fact, Brown and Taylor (1997) found that the Asay model, when run over a subset of the data used in this study (1 June 1993 to 30 June 1994), showed little pricing bias over very short-dated options ( $\mathrm{T}<30$ days), with some overpricing evident in longer-dated options $(30<\mathrm{T}<90$ days). This study was limited to options within the "short" period of this study - options 3 calendar months or less from their expiry date. Table 8 shows the results obtained in this study for the subset analysed in the Brown and Taylor (1997). 
Table 8: Short-Dated Contracts Similar to Those Analysed by Brown and Taylor (1997) (using NMIV)

\begin{tabular}{|r|r|r|r|r|r|r|}
\hline & \multicolumn{1}{|l|}{ MPE } & MAPE & MARPE & MEDARPE & $\begin{array}{l}\text { Number } \\
\text { of } \\
\text { Positive } \\
\text { Errors }\end{array}$ & $\begin{array}{l}\text { Total } \\
\text { Data } \\
\text { Count }\end{array}$ \\
\hline $9-1993$ & -3.133740631 & 23.46048757 & 0.141242866 & 0.064381145 & 227 & 514 \\
\hline $12-1993$ & -6.823064752 & 23.31384886 & 0.122841689 & 0.063228103 & 322 & 835 \\
\hline $3-1994$ & -2.276426344 & 33.10911016 & 0.127129449 & 0.057742322 & 513 & 1168 \\
\hline $6-1994$ & -10.35661271 & 31.28932249 & 0.22788932 & 0.06662098 & 240 & 692 \\
\hline Mean & -5.64746111 & $\mathbf{2 7 . 7 9 3 1 9 2 2 7}$ & $\mathbf{0 . 1 5 4 7 7 5 8 3 1}$ & $\mathbf{0 . 0 6 2 9 9 3 1 3 8}$ & $\mathbf{1 3 0 2}$ & $\mathbf{3 2 0 9}$ \\
\hline
\end{tabular}

Brown and Taylor used the nearest-the-money option from the previous trading day to calculate their implied volatility measure. Interestingly, the difference in the findings is significant. The findings of this study show a significant bias over this time period toward overpricing of the model, while Brown and Taylor found the model to be overpriced, with a mean error of -0.2776 , and mean absolute percentage error ${ }^{9}$ of only $13.14 \%$. This study contains substantially more matches in its sample over the same period - Brown and Taylor made only 2453 matches over the same time period. The major methodological difference in these studies is the pairing of the data. Brown and Taylor focus on a purely lead relationship between the futures trade and the option trade - the match is made to the option trade most closely following the futures trade. This assumption of a lead relationship, assuming that this is the major variation in methodology, appears to give a smaller level of mispricing.

To further analyse the Brown and Taylor findings, the June 1993 - July 1994 data was rematched in the manner of their study - each futures option trade is matched with the nearest occurring futures trade to within a minute after the futures option trade. The data was then analysed using the NMIV method as per their paper.

\footnotetext{
${ }^{9}$ Note particularly that this does not necessarily correspond to the mean absolute percentage error calculations given in this study as the exact method of calculation was not given in the paper.
} 
Table 9: Short-Dated Contracts Analysed in the Method of Brown and Taylor (1997)

\begin{tabular}{|r|r|r|r|r|r|r|}
\hline & \multicolumn{1}{|l|}{ MPE } & \multicolumn{1}{l|}{ MAPE } & \multicolumn{1}{l|}{ MARPE } & MEDARPE & $\begin{array}{l}\text { Number } \\
\text { of } \\
\text { Positive } \\
\text { Errors }\end{array}$ & $\begin{array}{l}\text { Total } \\
\text { Data } \\
\text { Count }\end{array}$ \\
\hline $9-1993$ & -2.37874 & 23.77816 & 0.117771 & 0.064793 & 170 & 375 \\
\hline $12-1993$ & -7.38673 & 23.87788 & 0.128582 & 0.065062 & 284 & 719 \\
\hline $3-1994$ & -0.65124 & 33.50513 & 0.127083 & 0.058158 & 489 & 1065 \\
\hline $6-1994$ & -2.75148 & 36.8315 & 0.253181 & 0.074042 & 242 & 636 \\
\hline Mean & $\mathbf{- 3 . 2 9 2 0 5}$ & $\mathbf{2 9 . 4 9 8 1 7}$ & $\mathbf{0 . 1 5 6 6 5 4}$ & $\mathbf{0 . 0 6 5 5 1 4}$ & $\mathbf{1 1 8 5}$ & $\mathbf{2 7 9 5}$ \\
\hline
\end{tabular}

The level of error is very similar to that found in the full analysis, despite having fewer matched transactions. The MAPE of $29.5 \%$ is very close to the MAPE of $27.8 \%$ found with the larger set, and the MARPE of $15.6 \%$ is only slightly larger than the previous finding of $15.5 \%$. The existence of an outlier in the March $1994^{10}$ NMIV calculation may cause some degree of error, although this was not remarked upon in their study and has not been removed for the purposes of this paper. Overall, there has been a very slight decrease in the accuracy of the sample. This contrasts significantly with the Brown and Taylor study. Not only did they match fewer transactions, but their mean absolute percentage error is somewhat lower at $13.14 \%$. Further examination of their work to determine the actual cause of these discrepancies is warranted. The simple matter of the different number of transactions between the data sets is of concern in itself.

\section{Conclusions}

This study has examined the mispricing effects of the Asay pure options pricing model on the SPI futures call option contract traded on the Sydney Futures Exchange between January 1993 and September 1995. The study found that there is a systemic bias in the model towards the overpricing of the futures option contract, and that the level of this overpricing is exacerbated when using near-the-money implied volatility measures, particularly on long-dated futures options. The use of an average volatility measure improved the performance of the Asay model on long-dated futures options, a result that merits further investigation, particularly when considering the increased frequency of use of long-dated options as compared to the use of long-dated futures contracts.

A number of issues have been raised during the course of this paper, that were outside the scope of the paper and hence have not been investigated in any detail. These issues are highly relevant to the study of futures options, and would make for interesting further research. The following is an outline of these areas, with a brief rationale for the interest that they may provoke.

\footnotetext{
${ }^{10}$ See Appendix $\mathrm{G}$ for time-to-maturity vs. volatility graph
} 


\subsection{Lead/Lag Relationships}

When matching the time stamped data, the focus of the matching process was on the nearness of the futures transaction to the futures option transaction, with little priority being given to whether a lead or lag relationship existed between these transactions. Only a small sample of the data was examined using a futures option transaction lead relationship, in order to contrast findings with those of Brown and Taylor (1997). A more detailed comparison of the effects of lead and lag relationships on the pricing effects of transactions would be a worthwhile investigation for a future date.

It would be interesting to refine the selection of time matched transactions further, and compare the pricing effect of matching futures transactions occurring before the futures option transaction, and compare that to the price effect of matching futures transactions occurring after the options transaction. This would illustrate better the lag effect of the futures transaction, should one exist. The fact that implied volatility is often calculated from the futures option transaction, and then used to price futures, may also show some lead effect from the futures option transaction to subsequent futures transactions. An investigation of futures pricing based on differing lead/lag pricing methods for futures options would be worthwhile.

\subsection{Long-Dated Futures Options}

Several issues have been raised in the Data section regarding the difficulty of assessing the pricing effects of long-dated options. A major issue is the relative lack of liquidity of both the options and the futures underlying the option contract.

It appears from the trading data that there is a lack of liquidity in the long-dated futures market. The vast majority of trades made are in the short-dated futures, and often days will go by without a trade being made in a futures contract that still has 12-18 months to expiry. However, the market for the futures options is much more liquid in the long-dated contracts. While the total number of options transactions is significantly lower than the futures, there are many occasions when there will be several transactions in a long-dated futures option contract on a day, without there being any transactions in the long-dated futures contract on that same day $^{11}$. This results in many futures options transactions failing to be matched with a futures transaction that occurs within the two-minute window. Intuitively, this is a sensible proposition - there is less certainty about future events, so an option is a preferable product to the straight futures contract for longer-dated contracts. Further study would match the futures option transaction with the closest futures transaction, without reference to a window of time, or a window significantly larger than that used for this study. Similar mispricing analysis would then be possible.

The differing use of long-dated futures contract and futures options contracts also raises some interesting questions about the effectiveness of the respective products for hedging portfolios. Further study in this area is possible.

\footnotetext{
${ }^{11}$ For example, $10^{\text {th }}$ June 1994. etc.
} 


\subsection{Implied Volatility Calculation}

There are a number of ways to calculate implied volatility ${ }^{12}$. The methods used in this paper is widely accepted in practice, however there are several other methods that would bear investigation.

Historical volatility analysis could be used to calculate the implied volatility. This is a traditional and accepted method, and has the benefit of being independent of the models used for valuation $^{13}$. This is particularly valid in the case of futures options, where the Asay model is widely used to generate implied volatility, and is also used to mark the contract to market. While substantial research has shown that implied volatility measurements are preferable to historical volatility measurements ${ }^{14}$, there is potential to examine this aspect of the pricing model more closely.

Implied volatility can be estimated using several techniques other than that used in this paper. These include weighted implied standard deviation methods, and methods involving variations on the moneyness of options. A comparison of mispricing effects under a more extensive range of methods of implied volatility calculations would be another area for further work ${ }^{15}$.

\footnotetext{
${ }^{12}$ For further discussion, see the section 2 of this paper.

13 Brace and Hodgson (1991) analyse historical volatility measures and conclude that there is little consistency between market prices and theoretical prices when using this volatility measure.

${ }^{14}$ Latane and Rendleman (1976), Brown and Shevlin (1983) among others.

15 Note that Brown and Taylor (1997) assert that the results found in their paper using near-the-money options were similar to results found using weighted implied standard deviation.
} 


\section{References}

Asay, Michael R., 1982, "A Note on the Design of Commodity Option Contracts", Journal of Futures Markets, Vol 2

Barone-Adesi, G., Whaley, Robert E., 1987, "Efficient Analytic Approximation of American Option Values”, Journal of Finance, Vol 42

Beckers, S., 1981, "Standard Deviations Implied in Option Prices as Predictors of Future Stock Price Variability", Journal of Banking and Finance, Vol 5

Benninga, Simon, 1989, "Numerical Techniques in Finance”, MIT Press

Black, Fisher, 1976, "The Pricing of Commodity Contracts”, Journal of Financial Economics, Vol 3

Brace, A., Hodgson, A., 1991, "Index Futures Option in Australia - An Empirical Focus on Volatility", Accounting and Finance, Vol 3

Brailsford, Tim and Heaney, Richard, 1998, "Investments", Harcourt Brace and Company

Brown, C. A., Taylor, S.D., 1997, "A Test of the Asay Model for Pricing Options on the SPI Futures Contract”, Pacific-Basin Finance Journal, Vol 5

Brown, R., Shevlin, T., 1983, "Modeling Option Prices in Australia Using the Black-Scholes Model", Australian Journal of Management

Chaudhury, M.M., 1995, "Some Easy-to-Implement Methods of Calculating American Futures Option Prices", Journal of Futures Markets, Vol 15

Handley, John, 2000, "An Empirical test of the Pricing of Variable Purchase Option Contracts", unpublished Working Paper, University of Melbourne.

Hull, John C.,1997, “Options, Futures and Other Derivatives”, Prentice Hall International

Latane, H., Rendleman, R.J., "Standard Deviation of Stock Price Ratios Implied by Option Premia", Journal of Finance, 1976

Lieu, Derming, 1990, "Option Pricing with Futures-Style Margining”, Journal of Futures Markets, Vol 10

Mayhew, Stewart, 1995, “Implied Volatility”, Financial Analysts Journal

Whaley, Robert E., 1986, "Valuation of American Futures Options: Theory and Empirical Tests", Journal of Finance, Vol 41 


\section{Appendix A}

\section{CalcVol}

This Matlab function calculates the implied volatility for each futures option transaction. The result is then written to a file.

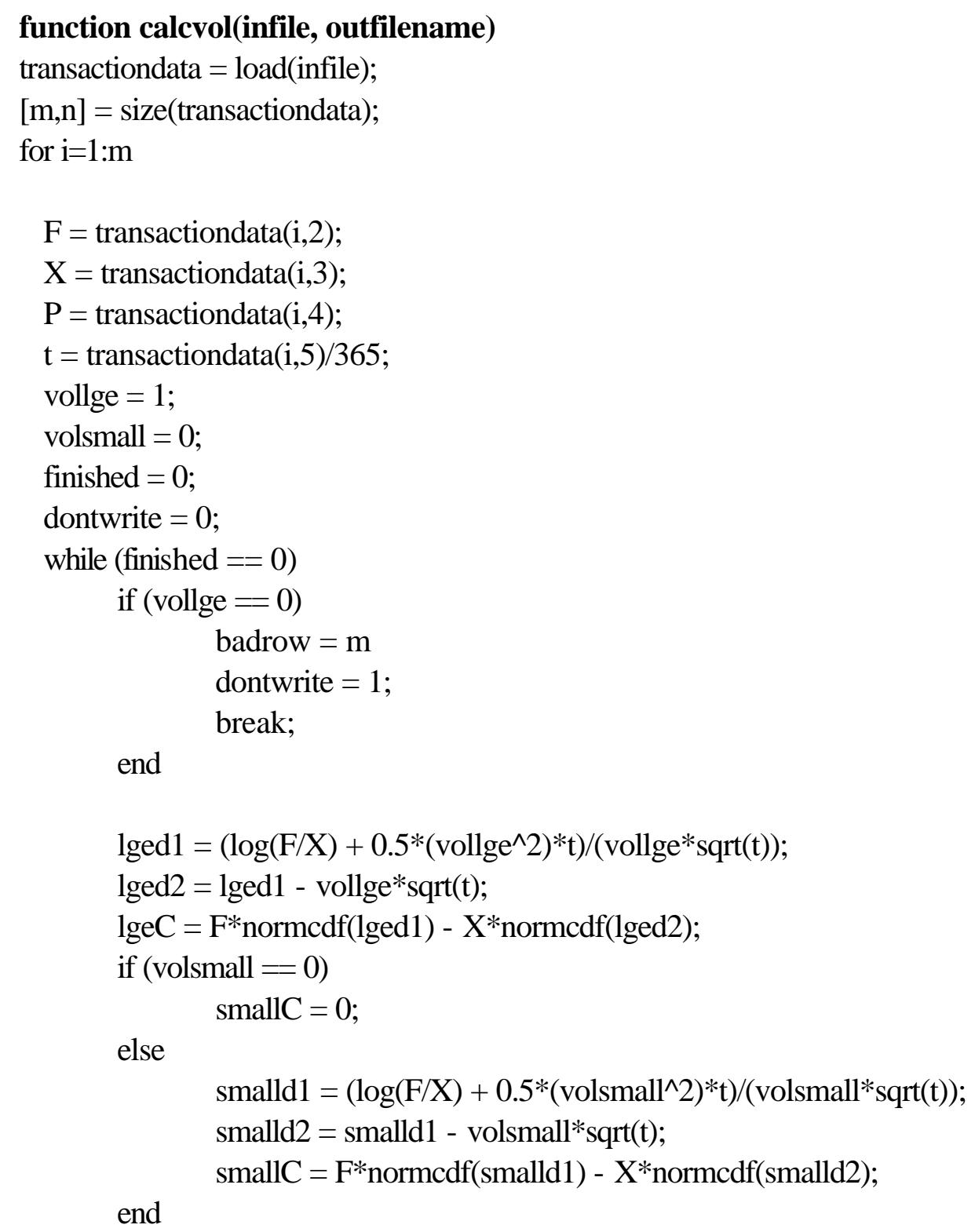


if (lgeC $-\mathrm{P}<0.00001 \& \operatorname{lge} \mathrm{C}-\mathrm{P}>=0$ )

transactiondata $(\mathrm{i}, 6)=$ vollge;

finished $=1$;

else

if (smallC $-\mathrm{P}<0.00001 \&$ smallC $>0 \&$ smallC $-\mathrm{P}>=0$ )

transactiondata $(\mathrm{i}, 6)=$ volsmall;

finished = 1 ;

else

volavg $=($ vollge + volsmall $) / 2$;

$\mathrm{d} 1=\left(\log (\mathrm{F} / \mathrm{X})+0.5^{*}\left(\text { volavg }^{\wedge} 2\right)^{*} \mathrm{t}\right) /(\operatorname{volavg} * \operatorname{sqrt}(\mathrm{t}))$;

$\mathrm{d} 2=\mathrm{d} 1$ - volavg*sqrt $(\mathrm{t})$

$\mathrm{C}=\mathrm{F}^{*}$ normcdf(d1) - $\mathrm{X}^{*}$ normcdf(d2);

if $\mathrm{C}<\mathrm{P}$

volsmall $=$ volavg;

else

vollge = volavg;

end

end

end

end

end

// end while loop

// end for loop 


\section{Appendix B}

\section{FindIV}

This function matches the implied volatility for the previous days transactions with the current days transactions.

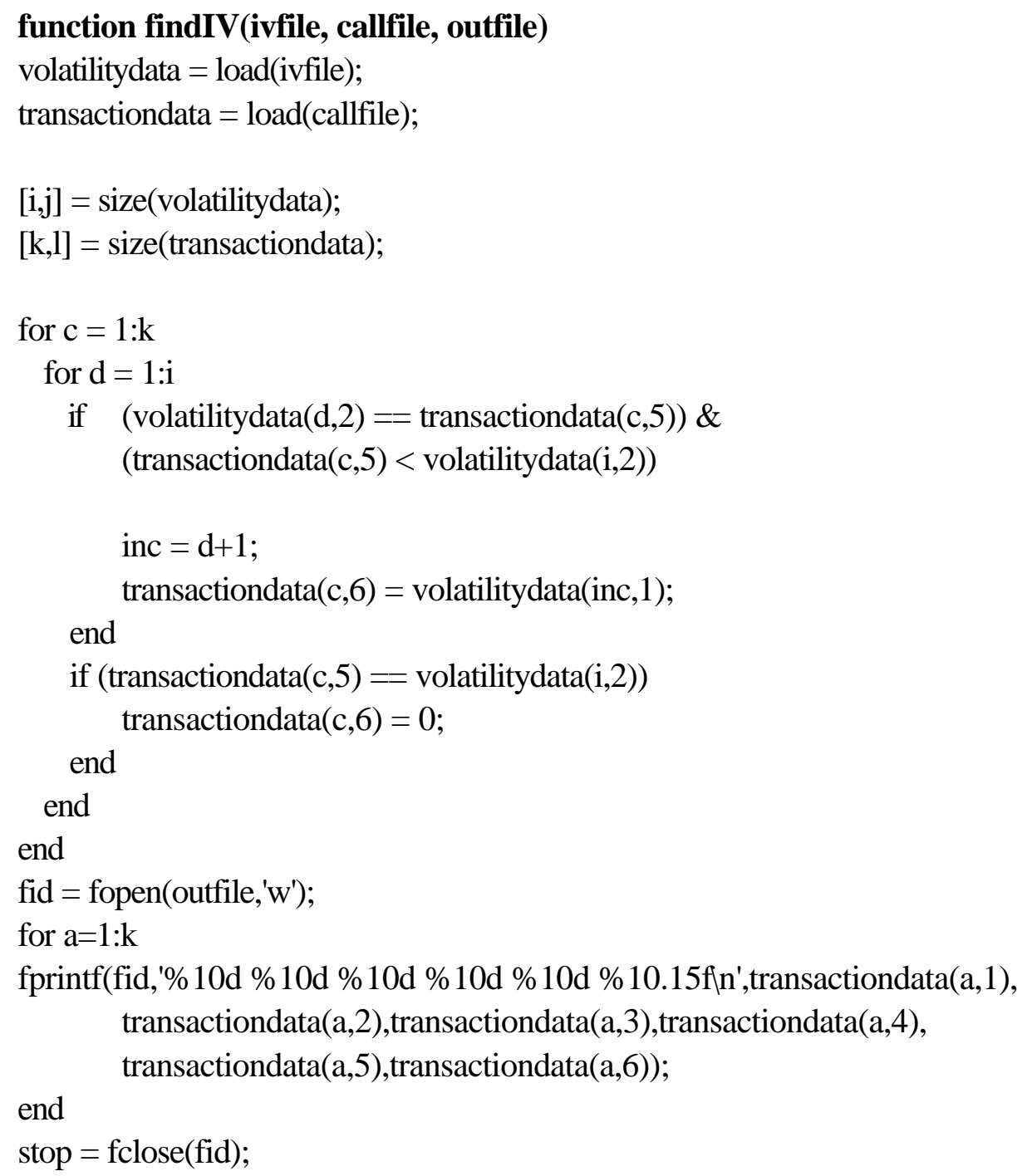




\section{Appendix C}

\section{DoPrice}

This function is the controller function for the calculation of the Asay price, and determination of the error data for each data set.

\section{function doPrice(infile, outfile)}

$$
\begin{aligned}
& \text { optiondata = load(infile); } \\
& \text { valid =0; } \\
& {[\mathrm{m}, \mathrm{n}]=\text { size (optiondata); }} \\
& \mathrm{j}=1 ; \\
& \text { for } \mathrm{i}=1: \mathrm{m} \\
& \quad \text { if }(\text { optiondata }(\mathrm{i}, 6)>0 \text { ) }
\end{aligned}
$$

// the transaction price is recorded in an array for comparison against the calculated price

ActualPrice $(\mathrm{j})=$ optiondata $(\mathrm{i}, 4)$;

// the Asay price is calculated from the futures trade price, the futures option strike price, the time to maturity and the implied volatility

$$
\begin{array}{r}
\text { CalculatedPrice }(\mathrm{j})=\quad \begin{array}{r}
\text { asay }(\text { optiondata }(\mathrm{i}, 2), \text { optiondata }(\mathrm{i}, 3), \\
\text { optiondata }(\mathrm{i}, 6), \text { optiondata }(\mathrm{i}, 5)) ;
\end{array}
\end{array}
$$

$$
\mathrm{j}=\mathrm{j}+1
$$

end

end

[MPE, MAPE, MARPE, MEDARPE, NumPos, TotalCount] = AsayErrors(ActualPrice, CalculatedPrice);

fid = fopen(outfile,'w');

fprintf(fid,'MPE, MAPE, MARPE, MEDARPE, NumPos, TotalCount $\backslash n \quad$ '); fprintf(fid,'\%10.15f, \%10.15f, \%10.15f, \%10.15f, \%10.15f, \%10.15f $\quad \ln ^{\prime}, \mathrm{MPE}$, MAPE, MARPE, MEDARPE, NumPos, TotalCount);

stop $=$ fclose $($ fid $)$; 


\title{
Appendix D
}

\begin{abstract}
Asay
This function calculates the Asay expected price based on the futures transaction price, the futures option strike price, the futures option transaction price and the implied volatility.
\end{abstract}

function $\mathbf{C}=\operatorname{asay}(\mathbf{F}, \mathbf{X}, \mathrm{vol}, \mathrm{t})$

$\mathrm{d} 1=\left(\log (\mathrm{F} / \mathrm{X})+0.5 *\left(\operatorname{vol}^{\wedge} 2\right) *(\mathrm{t} / 365)\right) /\left(\operatorname{vol}^{*} \operatorname{sqrt}(\mathrm{t} / 365)\right) ;$

$\mathrm{d} 2=\mathrm{d} 1-\operatorname{vol} * \operatorname{sqrt}(\mathrm{t} / 365)$;

$\mathrm{C}=\mathrm{F}^{*}$ normcdf(d1) - $\mathrm{X}^{*}$ normcdf(d2); 


\section{Appendix E}

\section{AsayErrors}

This function calculates the errors for each set of data.

function [MPE, MAPE, MARPE, MEDARPE, NumPos, TotalCount] = AsayErrors(OP, AP)

\% This function calculates the errors for the data

$\% \mathrm{OP}=$ Option Price

$\% \mathrm{AP}=$ Asay Calculation Price

\%Note: we assume that AP, OP have the same dimensions

$[\mathrm{m} \mathrm{n}]=\operatorname{size}(\mathrm{AP})$

$[\mathrm{o} \mathrm{p}]=\operatorname{size}(\mathrm{OP})$;

if $(\mathrm{m} \sim=\mathrm{o}) \mid(\mathrm{n} \sim=\mathrm{p})$

error ('The array sizes are different. There is an error in the data');

end;

$\%$ MPE Mean Pricing Error

$\mathrm{MPE}=0$;

$\%$ MAPE Mean Absolute Pricing Error

$\mathrm{MAPE}=0$

\%MARPE Mean Absolute Relative Pricing Error

MARPE $=0$;

$\%$ MEDARPE Median Absolute Relative Pricing Error

MEDARPE $=0$;

$\%$ NumPos Number of positive errors ie observed price is larger than

\%the Asay model derived price

NumPos = 0;

for counter $=1: \mathrm{n}$

asayerror $=\mathrm{OP}($ counter $)-\mathrm{AP}($ counter $)$;

$\mathrm{MPE}=\mathrm{MPE}+$ asayerror;

MAPE $=$ MAPE + abs(asayerror);

MARPE $=$ MARPE + abs (asayerror $) / \mathrm{OP}($ counter $)$;

errorarray $($ counter $)=$ abs (asayerror $) / \mathrm{OP}($ counter $)$;

if asayerror $>=0$

NumPos $=$ NumPos +1 ;

end;

end;

$\mathrm{MPE}=\mathrm{MPE} / \mathrm{n}$;

MAPE $=$ MAPE $/ \mathrm{n}$;

MARPE $=$ MARPE $/ \mathrm{n}$;

TotalCount $=\mathrm{n}$;

MEDARPE = median(errorarray); 


\section{Appendix F}

Time to Maturity vs Volatility - AIV

Volatility vs Time To Maturity - AIV

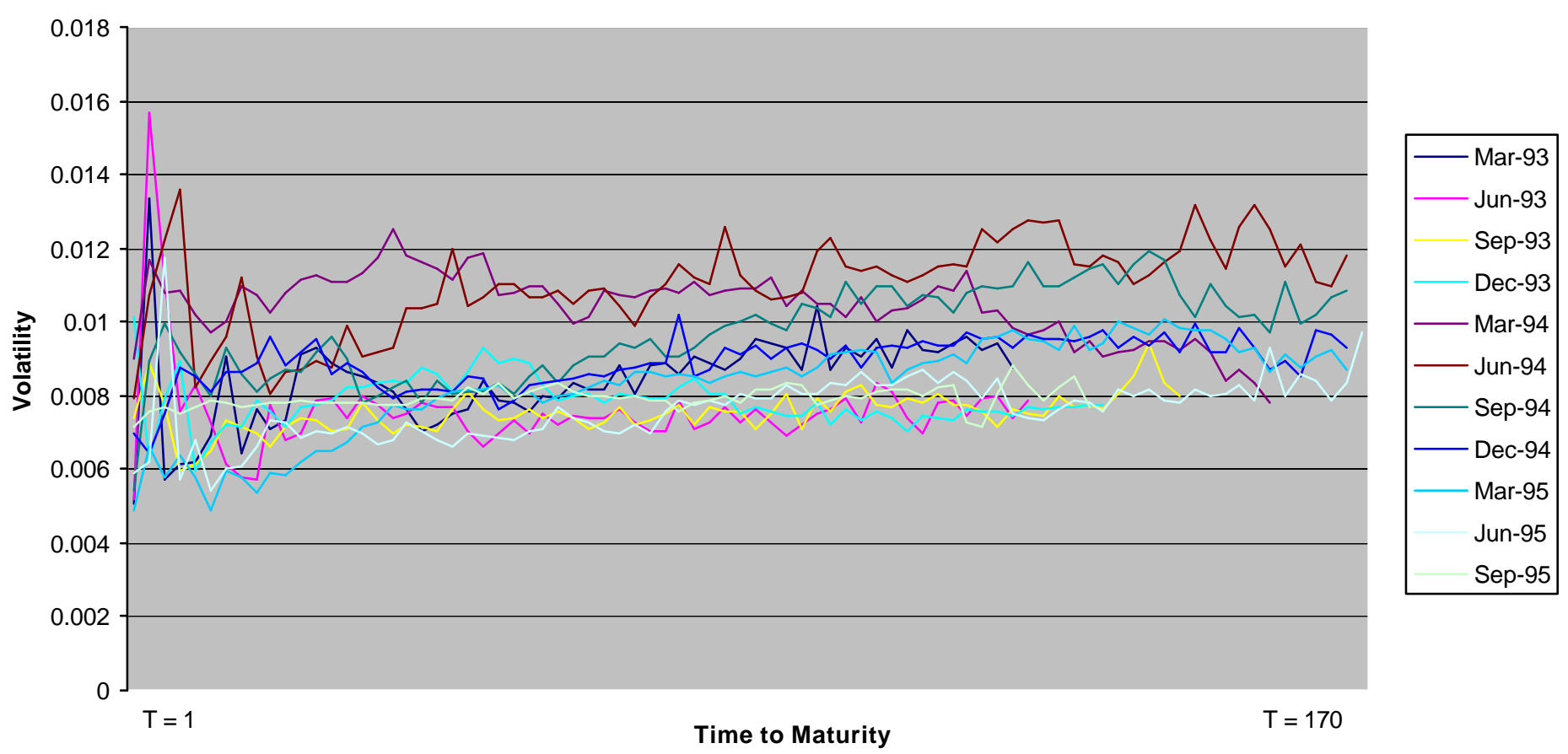




\section{Appendix G}

Time to Maturity vs Volatility - NMIV

Volatility vs Time To Maturity - NMIV

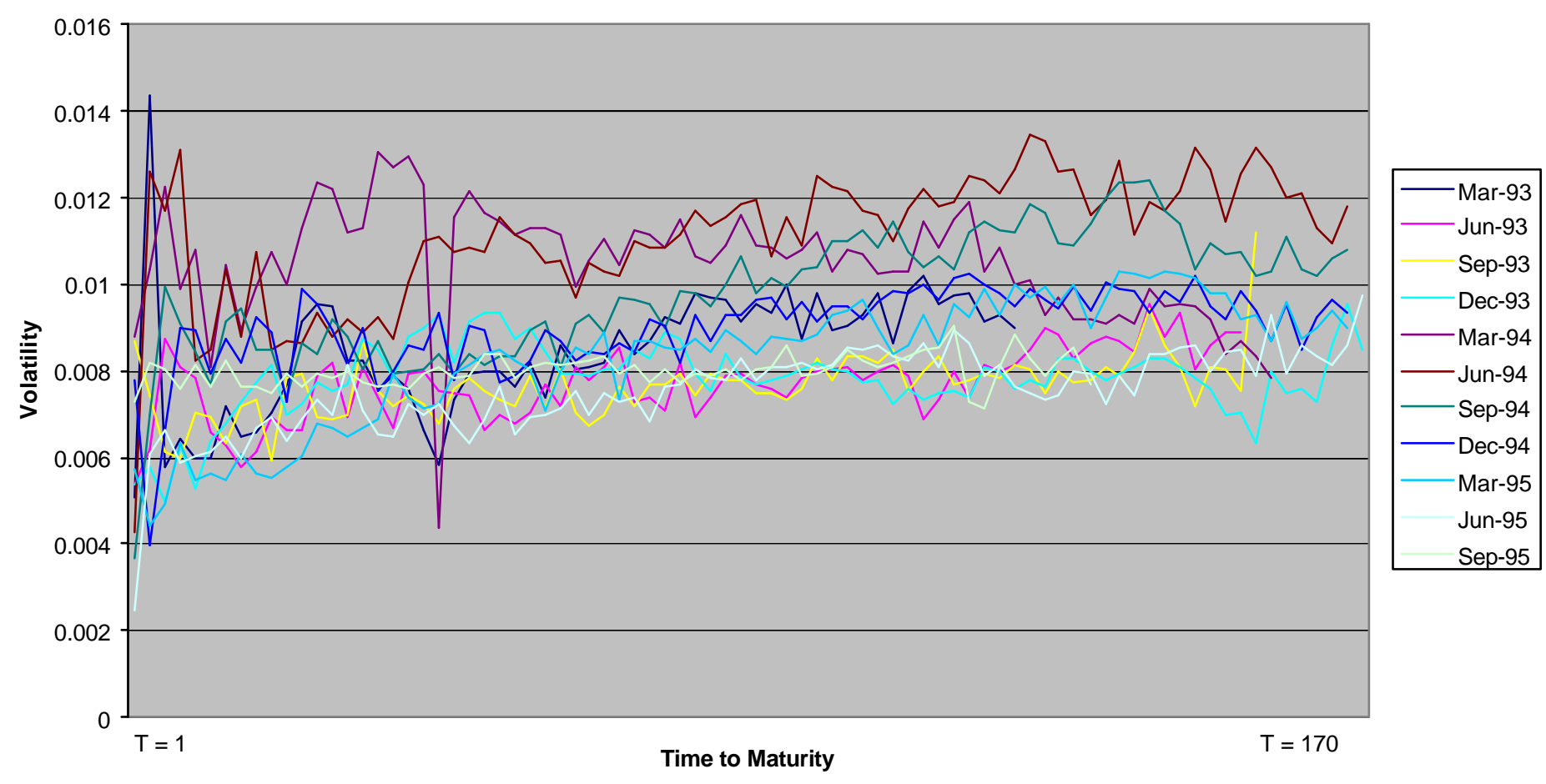

